\title{
Study on Simulation Method of Virtual Material for Modal Characteristics of Steel-BFPC Joint Surface
}

\author{
Liaoning Technical University \\ Yu Chen \\ Liaoning Technical University \\ Ping $X u$ \\ Liaoning Technical University \\ Xing-Yuan Zhang \\ Liaoning Technical University

\section{Ying-Hua Yu} \\ Liaoning Technical University \\ Xiao-Jing Li \\ Tangshan College
}

Jiaxing Shen ( $\sim 329833309 @ q q . c o m$ )

\section{Original Article}

Keywords: Steel-BFPC joint surface, Machine tool, Virtual materials, Finite element simulation, Modal analysis

Posted Date: January 13th, 2021

DOl: https://doi.org/10.21203/rs.3.rs-143569/v1

License: (c) (i) This work is licensed under a Creative Commons Attribution 4.0 International License.

Read Full License 


\section{Title page}

\section{Study on Simulation Method of Virtual Material for Modal Characteristics of Steel-BFPC Joint Surface}

Jia-Xing Shen, born in 1990, is a lecturer and master tutor at Research Institute of Technology and Equipment for the Exploitation and Utilization of Mineral Resources, Liaoning Technical University, China. He received his PhD degree from Liaoning Technical University, China, in 2018. His main research interests include mechanical system dynamics analysis and control.

Tel: +86-13841824339; E-mail: shenjiaxing@Intu.edu.cn, 329833309@qq.com

Yu Chen, born in 1991, is a lecturer at the college of Mechanical Engineering, Chaohu University. He received his master's degree from Liaoning Technical University, China, in 2018. He's studying in Liaoning Technical University for a doctorate, in 2020. His research interests are mechanical system dynamics analysis and control.

Email: cy3059555@163.com

Ping Xu, born in 1964, is currently a professor and a $\mathrm{PhD}$ candidate supervisor at School of Mechanical Engineering, Liaoning Technical University, China. His main research interests include mechanical system dynamics analysis and control.

E-mail: lnxuping@163.com

Xing-Yuan Zhang, born in 1980, is currently an associate professor and master tutor at School of Mechanical Engineering, Liaoning Technical University, China. His main research interests include mechanical friction and wear.

E-mail: zxyuan001@163.com

Ying-Hua Yu, born in 1965, is currently a professor and a PhD candidate supervisor at School of Mechanical Engineering, Liaoning Technical University, China. Her main research interests include mechanical system dynamics analysis and control.

E-mail: xuvicky199128@163.com

Xiao-Jing Li, born in 1988, is a lecturer of Key Lab of Intelligent Equipment Digital Design and Process Simulation, Hebei Province, Tangshan University, China. She received her PhD degree from Liaoning Technical University, China, in 2019. Her research interests include mechanical system dynamics analysis and control.

E-mail: lixiaojingre@163.com

Corresponding author: Jia-Xing Shen_E-mail: shenjiaxing@lntu.edu.cn, 329833309@qq.com 


\title{
Study on Simulation Method of Virtual Material for Modal Characteristics of Steel-BFPC Joint Surface
}

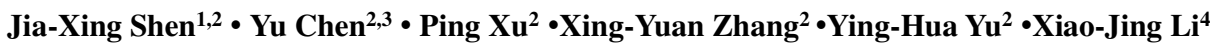

Received June xx, 201x; revised February xx, 201x; accepted March xx, 201x

(C) Chinese Mechanical Engineering Society and Springer-Verlag Berlin Heidelberg 2017

\begin{abstract}
Basalt fiber polymer concrete (BFPC) machine tool has the properties of lightweight and high damping, and the BFPC machine tool has excellent vibration damping and anti-vibration performance, which can improve the processing performance of the machine tool. There are many steel-BFPC joint surfaces in the machine tool, and these joint surfaces have a key influence on the dynamic performance such as the modal performance of the machine tool. In order to establish a virtual material simulation analysis method for modal characteristics of steel-BFPC joint surface, the detection principle of contact parameters of steel-BFPC joint surface was studied by using forced vibration theory, and the contact parameter detection experiment of steel-BFPC joint surface was designed. The virtual material model of BFPC joint surface was established, and the theoretical formulas of equivalent elastic modulus and equivalent shear modulus were derived based on the identified parameters of the BFPC joint surface. For the correctness of the analysis theory, a BFPC bed was taken as an example to study the modal performance of the BFPC bed by means of experiment and virtual material simulation analysis, respectively. The results of simulation analysis were compared with the experimental results. The results show that the maximum error of the natural frequency is only $6.23 \%$, and the modes of each order are consistent, which prove the effectiveness and accuracy of the virtual material
\end{abstract}

Jia-Xing Shen

shenjiaxing@lntu.edu.cn,329833309@qq.com

1 Research Institute of Technology and Equipment for the Exploitation and Utilization of Mineral Resources, Liaoning Technical University, Fuxin 123000, China

2 School of Mechanical Engineering, Liaoning Technical University, Fuxin 123000, China

3 College of Mechanical Engineering, Chaohu University, Chaohu, 238000, China

4 Key Lab of Intelligent Equipment Digital Design and Process Simulation, Hebei Province, Tangshan University, Tangshan 063000, China simulation analysis method.

Keywords:

Steel-BFPC joint surface - Machine tool - Virtual materials •

Finite element simulation $\bullet$ Modal analysis

\section{Introduction}

High-speed cutting machine tools can significantly improve the quality of the machined surface, but high-speed machine tools are particularly sensitive to vibration due to the high speed of the spindle [1-4]. Traditional high-speed cutting machine tools are mostly made of metal materials (such as steel and cast iron), resulting in their poor vibration damping, vibration resistance and poor lightweight performance [5,6]. Therefore, designers and users are not completely satisfied with the performance of high-speed machine tools made of traditional materials. Studies have shown that the machine bed made of mineral composite materials can have excellent vibration damping and vibration resistance in a wide range of excitation frequency, which makes the overall performance of the machine tool more superior [7-10]. For example, CHO designed a concrete machine tool workbench, the quality of the machine tool workbench is reduced by $36.8 \%$ and the structural rigidity is increased by $16 \%$, which can effectively improve the low-order natural frequency of the machine tool to avoid resonance [9]. SUH and LEE have manufactured a polymer concrete high-speed CNC milling machine, which has high damping $(2.93 \%-5.69 \%)$ in a wide frequency range [10].

In traditional material machine tools, $60 \%$ to $80 \%$ of the total machine stiffness is provided by the joint surface [11-13]. 80\% 90\% of the total damping of the machine tool comes from the joint surface [14-16]. More than $60 \%$ of machine tool vibration problems are related to the dynamic performance of the machine tool joint surface [17-21]. In mineral composite machine tools, there are a large number 
of mineral composite material-metal joint surfaces, such as the joint surfaces of metal guide rails and mineral composite machine tool foundation parts, and the joint surfaces of metal embedded parts and mineral composite machine tool foundation parts. These joint surfaces have a key impact on the dynamic performance of mineral composite material machine tools. This type of joint surface is quite different from the bimetal joint surface of traditional material machine tools in terms of constituent materials and the static and dynamic properties of the joint surface. In order to explore the contact parameter detection method of the joint surface of the mineral composite machine tool and the simulation analysis method of the dynamic performance. In this paper, a typical mineral composite material machine tool (basalt fiber polymer concrete machine tool) is used as the research object. The contact parameters of the steel-BFPC joint surface are tested through experiments. The modal analysis model of the steel-BFPC joint surface is established using virtual material theory.

The full paper consists of 5 sections. In Section 2, the principle of dynamic parameter detection of steel-BFPC joint surface is studied and the detection method of dynamic parameters of steel-BFPC joint surface is designed. Section 3 establishes a virtual material simulation model of the steel-BFPC joint surface and derives the equivalent parameter calculation method of the virtual material. In Section 4, a BFPC bed containing a steel-BFPC joint surface is studied, and the modal performance of the BFPC bed is investigated by means of experimental study and virtual material simulation analysis respectively to verify the correctness and accuracy of the study. Two key conclusions are summarized in Section 5.

\section{Detection Principle of Contact Parameters of Steel-BFPC Joint Surface}

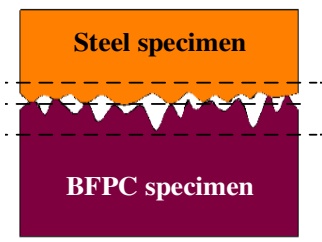

(a)

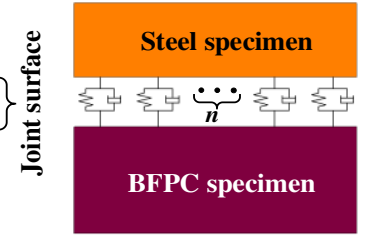

(b)
Figure 1 Equivalent model of steel-BFPC joint surface

The machined surfaces of steel and BFPC specimens are rough, and there are many micro-peaks on their surfaces. The steel and BFPC specimens contact and extrude to form a steel-BFPC joint surface, as shown in Figure 1(a). The dynamic characteristics of the joint surface are determined by the contact characteristics of these peaks.
Each group of contacting peaks can be regarded as a set of spring damping units $[7,22,23]$, so the steel-BFPC joint surface can be equivalent to the theoretical model in Figure 1(b).

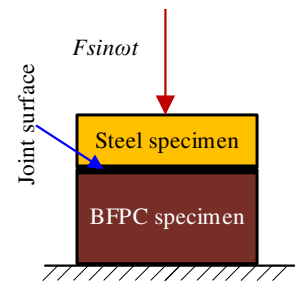

(a)

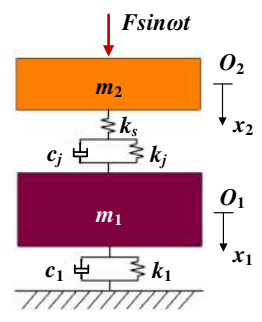

(b)
Figure 2 Steel-BFPC joint surface and its equivalent dynamic model

The dynamic parameters of the steel-BFPC joint surface are detected by means of sinusoidal excitation, as shown in Figure 2. The equivalent dynamic model of the steel-BFPC joint surface is shown in Figure 2(b), assuming that the total stiffness and total damping of the steel-BFPC joint surface are $k_{c}$ and $c_{j}$, respectively. The mass of the BFPC specimen is $m_{1}$. The total stiffness and total damping of the BFPC specimen itself and the joint surface formed by the contact between the BFPC specimen and the ground are $k_{1}$ and $c_{1}$, respectively. The mass and stiffness of the steel specimen are $m_{2}$ and $k_{\mathrm{s}}$, respectively. The damping of steel is very small compared with BFPC material and steel-BFPC joint surface, so its influence is ignored in the analysis model of Figure 2(b). There is a sinusoidal excitation force Fsin $\omega t$ in the center of the upper surface of the steel specimen. According to Figure 2(b), the vibration equation of the steel-BFPC joint surface piece can be obtained as

$$
\begin{gathered}
{\left[\begin{array}{cc}
m_{1} & 0 \\
0 & m_{2}
\end{array}\right]\left\{\begin{array}{l}
\ddot{x}_{1} \\
\ddot{x}_{2}
\end{array}\right\}+\left[\begin{array}{cc}
c_{j}+c_{1} & -c_{j} \\
-c_{j} & c_{j}
\end{array}\right]\left\{\begin{array}{l}
\dot{x}_{1} \\
\dot{x}_{2}
\end{array}\right\}+} \\
{\left[\begin{array}{cc}
k^{\prime}+k_{1} & -k^{\prime} \\
-k^{\prime} & k^{\prime}
\end{array}\right]\left\{\begin{array}{l}
x_{1} \\
x_{2}
\end{array}\right\}=\left\{\begin{array}{c}
0 \\
F \sin \omega t
\end{array}\right\}}
\end{gathered}
$$

Where $k$ ' is the equivalent stiffness of the steel specimen and the joint surface, because the stiffness $k_{s}$ of the steel specimen is much greater than the contact stiffness $k_{j}$ of the steel-BFPC joint surface, so $k^{\prime}=\left(k_{j}^{-1}+k_{s}^{-1}\right)^{-1} \approx k_{j}$.

By solving equation (1), the amplitude $B_{1}$ and phase angle $\psi_{1}$ of the BFPC specimen, the amplitude $B_{2}$ and phase angle $\psi_{2}$ of the steel specimen are obtained as 


$$
\left\{\begin{array}{l}
B_{1}=F \sqrt{\frac{h^{2}+d^{2}}{a^{2}+b^{2}}}, \psi_{1}=\arctan \left(\frac{b h-a d}{a h+b d}\right) \\
B_{2}=F \sqrt{\frac{f^{2}+d^{2}}{a^{2}+b^{2}}}, \psi_{2}=\arctan \left(\frac{b f-a d}{a f+b d}\right)
\end{array}\right.
$$

Where $a=\left(k_{1}+k_{j}-m_{1} \omega^{2}\right)\left(k_{j}-m_{2} \omega^{2}\right)-k_{j}^{2}-c_{1} c_{j} \omega^{2}, \quad d=c_{j} \omega$, $f=\left(k_{1}+k_{j}\right)-m_{1} \omega^{2} \quad, \quad g=\left(c_{1}+c_{j}\right) \omega \quad, \quad h=k_{j}$, $b=\left(k_{1}-m_{1} \omega^{2}-m_{2} \omega^{2}\right) c_{j} \omega+\left(k_{j}-m_{2} \omega^{2}\right) c_{1} \omega$.

Exciting force amplitude $F$ and angular frequency $\omega$ are set by the computer, which are known conditions. Then $B_{1}, B_{2}, \psi_{1}, \psi_{2}, m_{1}, m_{2}$ are measured through experiments. According to the above known conditions and equation (2), the stiffness $k_{j}$ and damping $c_{j}$ of the steel-BFPC joint surface can be solved.

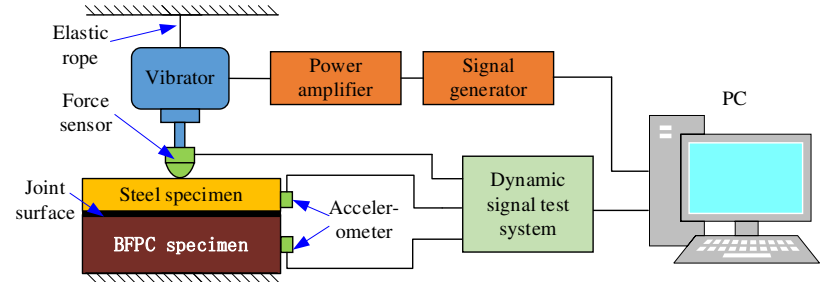

Figure 3 The principle of joint surface parameter detection

The principle of detecting the parameters of the steel-BFPC joint surface is shown in Figure 3, and the experimental site is shown in Figure 4. The exciting force of the electromagnetic exciter acts on the center of the upper surface of the steel specimen. The frequency of the exciting force is controlled by a computer and a signal generator, and the amplitude of the exciting force is controlled by a power amplifier. The force sensor is used to detect the magnitude of the exciting force acting on the steel specimen. Two acceleration sensors are used to detect the vibration response of the steel specimen and the BFPC specimen. The data detected by the force sensor and acceleration sensor are transmitted to the dynamic signal test system for recording and processing. The quality of the steel specimen and the BFPC specimen is measured with an electronic scale. Finally, according to the experimental data, the stiffness $k_{j}$ and damping $c_{j}$ of steel BFPC joint surface can be obtained by solving equation (2) with MATLAB software.

When the exciting direction of the vibration exciter is the tangential direction of the joint surface and the signal picking direction of the acceleration sensor is set as the tangential direction, the corresponding tangential vibration of the joint surface can be detected, and then the tangential dynamic parameters of the steel BFPC joint surface can be solved according to equation (2).

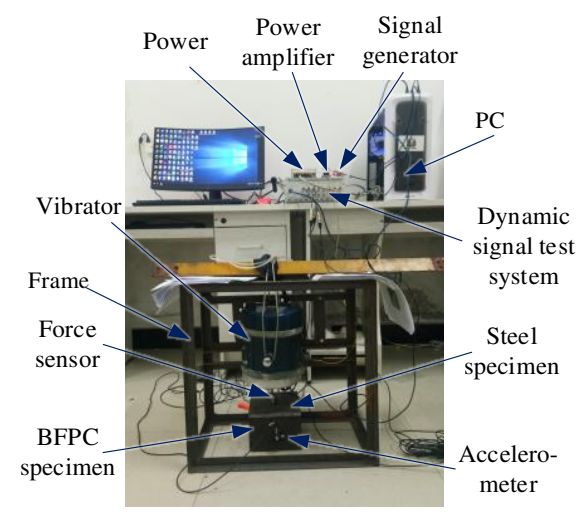

Figure 4 Experimental site

\section{Virtual Material Model of Steel-BFPC Joint Surface}

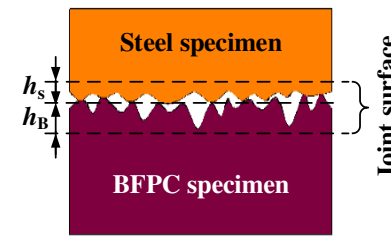

(a)

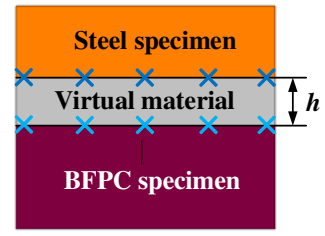

(b)
Figure 5 Virtual material model of steel-BFPC joint surface

Although the equivalent spring damping element can be used to simulate the mechanical properties of the steel-BFPC joint surface, the equivalent spring damping element cannot simulate the thermal mechanical coupling contact properties of the steel-BFPC joint surface. Moreover, the layout of spring damping elements and the number of spring damping elements have great influence on the accuracy of the analysis results. Therefore, virtual material is used to simulate the contact performance of steel-BFPC joint surface. As shown in Figure 5, a thin virtual material layer is added between the steel specimen and the BFPC specimen, and the virtual material layer is connected with the metal specimen and the BFPC specimen by binding contact, as indicated by ' $x$ ' in Figure 5 (b). Then the material performance parameters of the virtual material layer are defined to simulate the contact performance of the steel-BFPC joint surface. The different contact properties of the steel-BFPC joint surface are simulated by changing the material parameters of the virtual material. This method enables the theoretical analysis and finite element simulation to be better 
integrated, and contributes to the systematization of the joint surface research. The key material parameters of virtual material are modeled as follows.

\subsection{Equivalent modulus of elasticity}

The equivalent elastic modulus $E_{n}$ of the virtual material is the ratio of its normal stress $\sigma$ to its normal strain $\varepsilon$.

$$
E_{n}=\frac{\sigma}{\varepsilon}
$$

The normal contact stiffness of the steel-BFPC joint surface is $K_{n}$. When the normal load of the steel-BFPC joint surface is $F_{n}$, its normal deformation $\delta_{n}$ is

$$
\delta_{n}=\frac{F_{n}}{K_{n}}
$$

Assuming the thickness of the virtual material is $h$, its normal strain is

$$
\varepsilon=\frac{\delta_{n}}{h}
$$

The average normal stress of the virtual material is

$$
\sigma=\frac{F_{n}}{A_{a}}
$$

Where $A_{a}$ is the nominal contact area of the steel-BFPC joint surface.

Substituting equation (4) to equation (6) into equation (3), the equivalent elastic modulus is

$$
E_{n}=\frac{K_{n} h}{A_{a}}=K_{n}^{\prime} h
$$

Where $K_{n}^{\prime}$ is the unit normal contact stiffness of the steel-BFPC joint surface.

\subsection{Equivalent shear modulus of virtual material}

The equivalent shear modulus $G_{t}$ is the ratio of its shear stress $\tau$ to its shear strain $\gamma$

$$
G_{t}=\frac{\tau}{\gamma}
$$

The tangential contact stiffness of the steel-BFPC joint surface is $K_{t}$. When the tangential load of the steel-BFPC joint surface is $F_{t}$, the tangential deformation $\delta_{t}$ is

$$
\delta_{t}=\frac{P_{t}}{K_{t}}
$$

When the shear strain is micro, the shear strain $\gamma$ is approximately equal to

$$
\gamma \approx \tan \gamma=\frac{\delta_{t}}{h}
$$

The average shear stress of the virtual material is

$$
\tau=\frac{P_{t}}{A_{a}}
$$

Substituting equation (9) to equation (11) into equation (8), the equivalent shear modulus of the virtual material is

$$
G_{t}=\frac{K_{t} h}{A_{a}}=K_{t}^{\prime} h
$$

Where $K_{t}^{\prime}$ is the unit tangential contact stiffness of the steel-BFPC joint surface.

\subsection{Equivalent Poisson's ratio of virtual material}

When the steel-BFPC joint surface is subjected to a normal load, micro convex peaks that contact each other on the rough surface will deform in the normal and tangential directions. As shown in Figure 1 (a), there are many gaps between the convex peaks that cause the joint surface to be incomplete contact. Therefore, the tangential deformation of the micro convex peak will fill each gap. From the perspective of the entire joint surface, the overall tangential deformation of the steel-BFPC joint surface is zero, so it can be considered that the equivalent Poisson's ratio of the virtual material is zero [24,25].

\subsection{Equivalent thickness of virtual material}

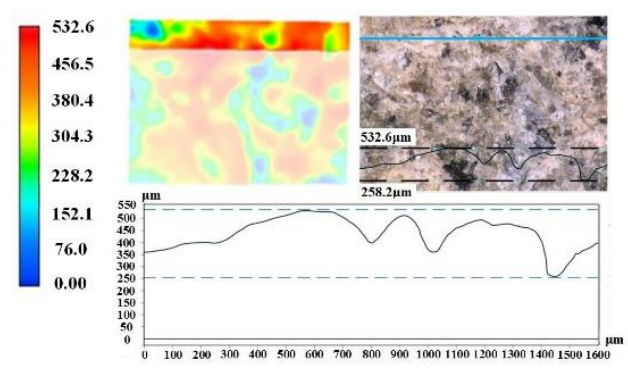

Figure 6 Surface morphology of BFPC

The equivalent thickness of the virtual material layer is determined by the height of the convex peak on the rough surface of the steel specimen and the BFPC specimen, and the thickness of the elastic, plastic and elastic-plastic deformation zone of the material. BFPC material is composed of different size aggregate, resin binder, basalt fiber and other components. The roughness of BFPC specimen after machining is usually around $\mathrm{Ra}$ 6.3, and its surface morphology is shown in Figure 6. According to Figure 6, the maximum value of micro convex peak is about $500 \mu \mathrm{m}$. Considering the deformation region of BFPC specimen, the thickness of the region is assumed to be $500 \mu \mathrm{m}$. So the equivalent thickness of BFPC specimen is $h_{B}=0.5+0.5=1 \mathrm{~mm}$. The roughness of the steel 
specimen is Ra 3.2, which is about half of that of BFPC specimen. It is assumed that the sum of the thickness of the micro convex peak and the thickness of the deformation area is $h_{s}=0.5 \mathrm{~mm}$. The total thickness of the virtual material is $h=1.5 \mathrm{~mm}$.

\subsection{Equivalent density of virtual material}

The equivalent density of the virtual material is the mass of the virtual layer divided by the volume of the virtual layer. Its equivalent density is

$$
\begin{gathered}
\rho=\frac{m_{s}+m_{B}}{V}=\frac{\rho_{s} V_{s}+\rho_{B} V_{B}}{V} \\
=\frac{\lambda\left(\rho_{s} A_{a} h_{s}+\rho_{B} A_{a} h_{B}\right)}{A_{a}\left(h_{s}+h_{B}\right)}=\frac{\lambda\left(\rho_{s} h_{s}+\rho_{B} h_{B}\right)}{\left(h_{s}+h_{B}\right)}
\end{gathered}
$$

Where $V$ is the volume of the virtual material. $V_{s}$ and $V_{B}$ are the volume of the micro convex layer of steel and BFPC. $m_{s}$ and $m_{B}$ are the masses of the micro convex layer of steel and BFPC. $\lambda$ is the contact area coefficient of the joint surface, which is the ratio of the actual contact area $A_{r}$ to the nominal contact area $A_{a} . \rho_{s}$ and $\rho_{B}$ are the densities of steel and BFPC.

\subsection{Relationship between contact area coefficient and load of steel-BFPC joint surface}

Majumder's research on rough surface shows that the machined rough surface has fractal characteristics [26-29]. Majumdar established an elastoplastic contact fractal model of rough surface according to the W-M fractal function. The contact area distribution density function of micro convex peaks on rough surfaces is $[30,31]$

$$
n(a)=\frac{D a^{D / 2}}{2 a^{(D / 2+1)}}, 0<a \leq a_{l}
$$

Where $a$ is the contact point area; $a_{l}$ is the largest contact point area; $D$ is the fractal dimension.

For machined surfaces, $D$ and roughness have the following relationship [15].

$$
D=\frac{1.528}{R_{a}^{0.042}}
$$

The contact area of the micro convex peak of the steel BFPC joint surface is

$$
a=\pi R \delta^{\prime}
$$

Where $\delta^{\prime}$ is the deformation size of the micro convex peak; $R$ is the curvature radius of the micro convex peak, and its size is

$$
R=\frac{a^{D / 2}}{\pi^{2} G^{D-1}}
$$

Where $G$ is the characteristic scale coefficient of W-M fractal function of the rough surface.

When the micro convex peak is elastically deformed, that is, the contact area $a$ is larger than the critical contact area $a_{c}$. According to Hertz contact theory, it can be known that the elastic contact load of the micro convex peak is

$$
F_{e}=\frac{4}{3} E R^{1 / 2} \delta^{3 / 2}
$$

Where $E$ is the composite elastic modulus, because the elastic modulus of BFPC is much smaller than that of steel, so $E=E_{B} /\left(1-\mu_{\mathrm{B}}^{2}\right) . E_{B}, \mu_{B}$ are BFPC's elastic modulus and Poisson's ratio.

Substituting equations (16) and (17) into (18), we can get

$$
F_{e}(a)=\frac{4 \sqrt{\pi} E G^{D-1} a^{(3-D) / 2}}{3}
$$

When the micro convex peak is plastically deformed, that is, the contact area $a$ is less than or equal to the critical contact area $a_{c}$, the plastic contact load of the micro convex peak is

$$
F_{p}(a)=\theta \sigma_{y} a
$$

Where $\theta$ is the relationship coefficient between material hardness $H$ and yield strength $\sigma_{y}, \theta=H / \sigma_{y}$.

When the maximum contact area $a_{l}$ of the micro convex peak of the joint surface is larger than the critical contact area $a_{c}$, the total load of the entire steel-BFPC joint surface is

$$
F=\int_{a_{c}}^{a_{l}} F_{e}(a) n(a) d a+\int_{0}^{a_{c}} F_{p}(a) n(a) d a
$$

The relationship between the real contact area of the steel-BFPC joint surface and the load is obtained by integrating equation (21) and performing dimensionless processing. 


$$
\left\{\begin{array}{c}
F^{*}=\lambda^{(D / 2)}\left[g_{1} \times g_{2}+g_{3}\right] \\
g_{1}=\frac{4 \sqrt{\pi} D G^{*(D-1)}}{3(3-2 D)}\left(\frac{2-D}{D}\right)^{D / 2} \\
g_{2}=\left[\frac{\lambda(2-D)}{D}\right]^{(3-2 D) / 2}-a_{c}^{*(3-2 D) / 2}, D \neq 1.5 \\
g_{3}=\theta \phi a_{c}^{*[(2-D) / 2]}\left(\frac{2-D}{D}\right)^{D / 2}
\end{array}\right.
$$

Where $\phi$ is the characteristic parameter of the material, $\phi=\sigma_{y} / E \cdot F^{*}, G^{*}$ and $a_{c}^{*}$ are dimensionless load, dimensionless characteristic scale coefficient and dimensionless critical contact area, respectively, they are $F^{*}=F /\left(E A_{a}\right), \quad G^{*}=G / \sqrt{A_{a}}$ and $a_{c}^{*}=G^{* 2} /\left[(\theta \phi / 2)^{2 /(D-1)}\right]$.

Substituting the relational expression $P=F / A_{a}=F^{*} E$ of the pressure and the dimensionless load into equation (22), the function relationship between the pressure and the contact area coefficient can be obtained.

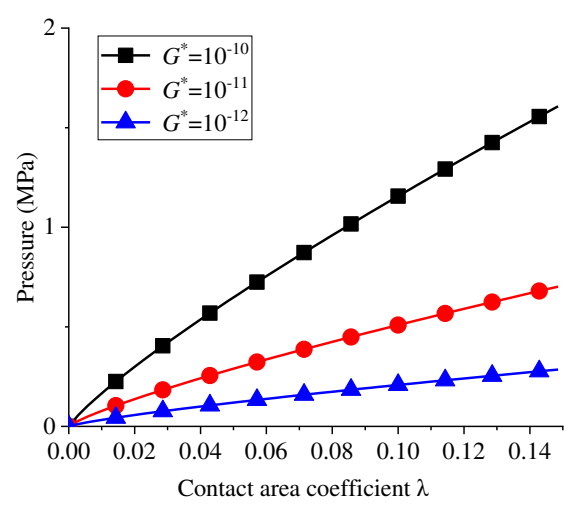

(a) $\operatorname{Ra} 3.2$

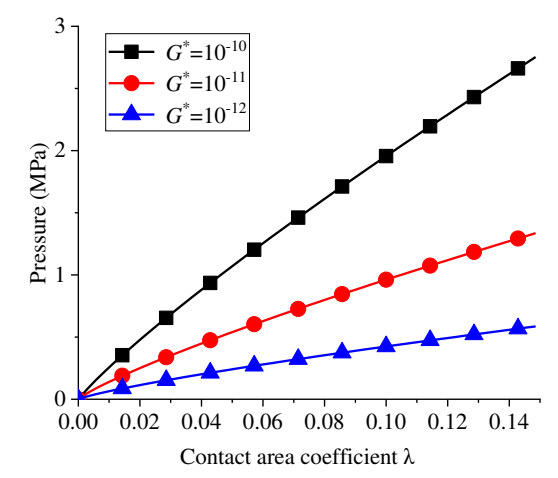

(b) $\operatorname{Ra} 6.3$

Figure 7 Relationship between the contact area coefficient of the joint surface and the pressure
The yield strength of BFPC is $128 \mathrm{MPa}$, the hardness is about $45 \mathrm{~N} / \mathrm{mm}^{2}$, the modulus of elasticity is $35 \mathrm{GPa}$, and the Poisson's ratio is 0.26 . In engineering applications, $G^{*}$ is usually $10^{-12}, 10^{-11}$ and $10^{-10}$. According to equation (22), the relation curve between contact area coefficient and pressure of steel-BFPC joint surface is shown in Figure 7. The pressure of the joint surface increases with the increase of the contact area coefficient and the characteristic scale coefficient $G^{*}$, and they have a non-linear relationship. This shows that in the case of the same roughness, to increase the actual contact area of the joint surface, it is necessary to provide more pressure to overcome the contact stiffness of the joint surface.

\section{Comparative verification analysis}

\subsection{Modal experimental characteristics of BFPC bed}

In order to test the accuracy of parameters detection and virtual material simulation analysis method of steel-BFPC joint surface, a BFPC bed is taken as the research object. Firstly, the modal performance of BFPC bed is tested by experiments. Then the normal and tangential stiffness of the steel-BFPC joint surface under the same working condition as the BFPC bed are determined by the parameter detection method in the Section 2. Finally, according to the measured stiffness, the equivalent parameters of virtual material layer are determined by virtual material theory, and the modal performance of BFPC bed is studied by simulation analysis. The experimental results are compared with the simulated results to verify the correctness of the theory.

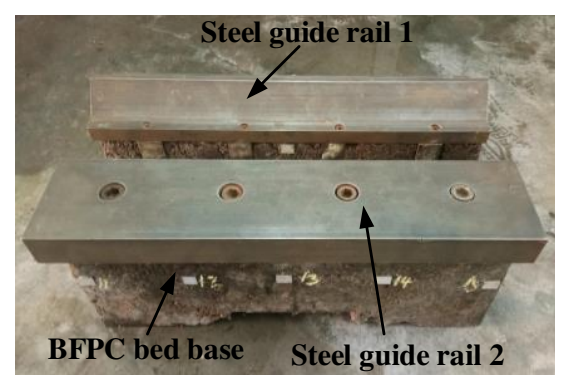

Figure 8 BFPC bed

As shown in Figure 8, the BFPC bed is mainly composed of steel guide rails 1,2 and the BFPC bed base. The steel-BFPC joint surface is composed of the contact surfaces of the steel guide rails and the BFPC bed base. 
The nominal contact area between the steel guide rail 1 and the BFPC bed base is $55000 \mathrm{~mm}^{2}$. The nominal contact area between the steel guide rail 2 and the BFPC bed base is $35000 \mathrm{~mm}^{2}$. The roughness of steel guide rails is $\mathrm{Ra}$ 3.2. The roughness of the BFPC bed base is approximately $\mathrm{Ra}$ 6.3. The load applied to the joint surface is $0.8 \mathrm{MPa}$.

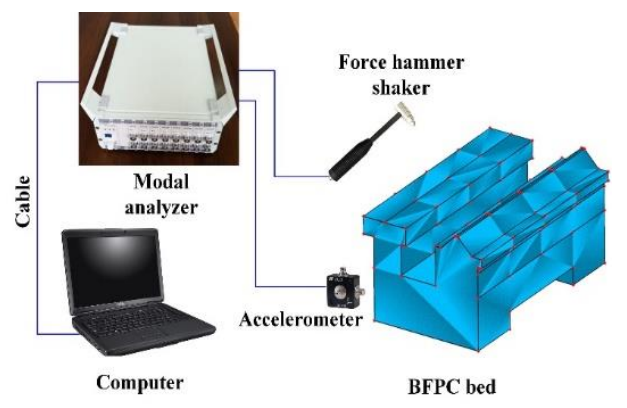

Figure 9 BFPC modal performance detection system

Figure 9 is the detection system of the modal performance of the BFPC bed. It mainly consists of computer, modal analyzer, accelerometer, hammer vibrator and cable. During the experiment, firstly, the BFPC bed is fixed on the horizontal ground, and then the computer, the modal analyzer, the force hammer shaker, and the accelerometer are connected with data cables according to Figure 9, and the accelerometer is pasted on the BFPC bed. The experimental site is shown in Figure 10. The force hammer shaker is used to knock the BFPC bed to make it vibrate and generate vibration signals. The accelerometer is used to collect the vibration response signals of each position of BFPC bed in turn. The signals of the force hammer shaker and accelerometer are input into the modal analyzer through the cables. The modal analyzer calculates the modal performance of BFPC bed by Poly Max method according to the excitation signal and acceleration response signal [32]. The computer is used to set the parameters of modal analyzer and display the calculation results.

The first three natural frequencies of the BFPC bed are measured through experiments, and they are $537.7 \mathrm{~Hz}$, 845.9 Hz, and $1100 \mathrm{~Hz}$. Figure 11 shows the vibration mode of the BFPC bed from the first order to the third order. The first-order mode is the vibration of the left side of the BFPC bed, the second-order mode is the overall vibration of the BFPC bed, and the third-order vibration of the BFPC bed is the "S"-shaped vibration on the right side of the bed.

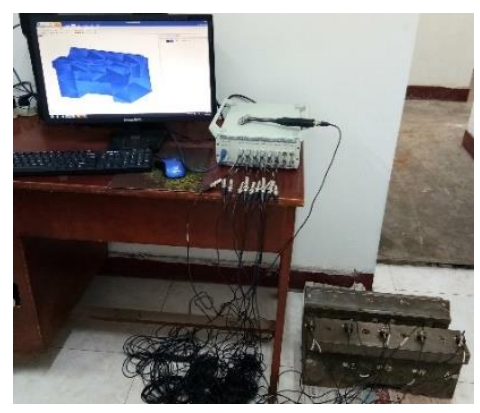

Figure 10 Modal experiment site of BFPC bed

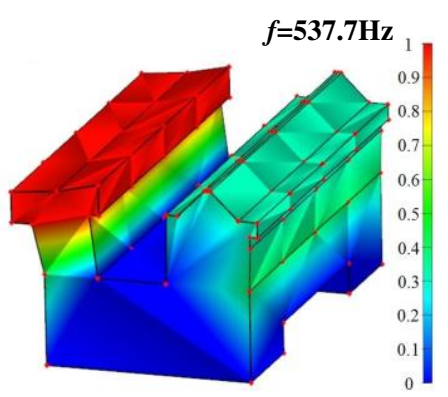

(a) First-order mode

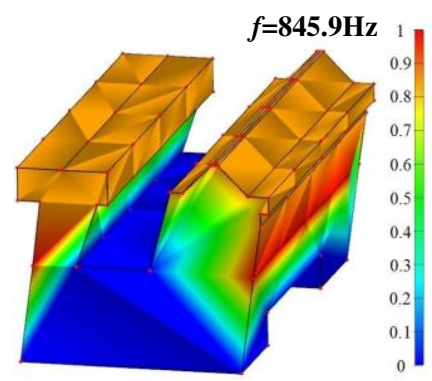

(b) Second-order mode

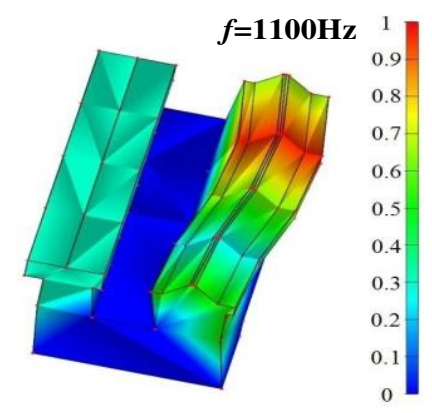

(c) Third-order mode

Figure 11 Experimental mode shape of BFPC bed 4.2 BFPC bed modal simulation analysis

The joint surface pressure of the BFPC bed is $0.8 \mathrm{MPa}$. 
The roughness of the steel guide rail is $\mathrm{Ra} 3.2$, and the roughness of the BFPC bed base is $\mathrm{Ra}$ 6.3. The detection device shown in Figure 4 is used to detect the contact stiffness of the steel-BFPC joint surface with the same roughness and pressure as the BFPC bed, and the test results are applied to the BFPC bed simulation analysis. The normal and tangential contact stiffness of the steel-BFPC joint surface measured by the experiment are $516237778 \mathrm{~N} / \mathrm{m}$ and $200020509 \mathrm{~N} / \mathrm{m}$, respectively. The normal contact stiffness is divided by the nominal contact area to obtain the unit normal contact stiffness of the steel-BFPC joint surface. The unit normal contact stiffness of the steel-BFPC joint surface is $22943.9 \mathrm{~N} /\left(\mathrm{m} \cdot \mathrm{mm}^{2}\right)$. Using the same method, the unit tangential contact stiffness of the steel-BFPC joint surface is obtained as $8889.8 \mathrm{~N} /\left(\mathrm{m} \cdot \mathrm{mm}^{2}\right)$. Damping has almost no effect on the modal shape and frequency of the BFPC bed, so the damping effect is ignored in the simulation. The material of guide rails is $\mathrm{C} 1045$, its density is $\rho_{s}=7890$ $\mathrm{kg} / \mathrm{m}^{3}$, elastic modulus is 200GPa, Poisson's ratio is 0.27 [33-35]. The material of the bed base is BFPC, its density is $\rho_{B}=2850 \mathrm{~kg} / \mathrm{m}^{3}$, elastic modulus is $35 \mathrm{GPa}$, Poisson's ratio is 0.26 . The equivalent performance parameters of the virtual material are obtained using formulas (7), (12), (13), (22), as shown in Table 1.

Table 1 Equivalent parameters of virtual material

\begin{tabular}{cccc}
\hline Parameters & $\begin{array}{c}\text { Elastic } \\
\text { modulus/GPa }\end{array}$ & $\begin{array}{c}\text { Shear modulus } \\
/ \mathrm{GPa}\end{array}$ & $\begin{array}{c}\text { Poisson's } \\
\text { ratio }\end{array}$ \\
\hline Values & 34.42 & 13.33 & 0 \\
\hline Parameters & Thickness $/ \mathrm{mm}$ & $\begin{array}{c}\text { Contact area } \\
\text { coefficient }\end{array}$ & $\begin{array}{c}\text { Density } \\
/\left(\mathrm{kg} \cdot \mathrm{m}^{-3}\right)\end{array}$ \\
\hline Values & 1.5 & 0.077 & 348.81 \\
\hline
\end{tabular}

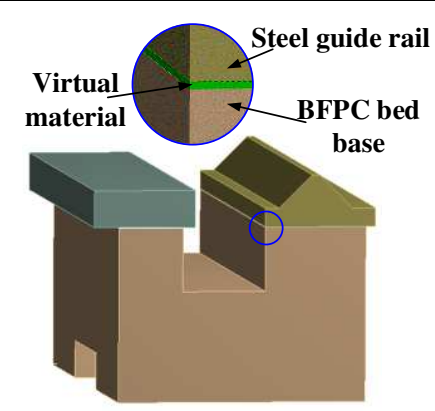

Figure 12 The virtual material model of the BFPC bed

The three-dimensional model of BFPC bed base and guide rails was built by Creo 2.0 directly. Because the virtual material method is used for the finite element simulation analysis, the Boolean operation is used to cut the solid element with a thickness of $1.5 \mathrm{~mm}$ as the virtual material layer at the contact position of the guide rail 1 and guide rail 2 and the BFPC bed base, as shown in Figure 12. ANSYS Workbench software is used to simulate the modal of BFPC bed with virtual material layer.

C1045 and BFPC are isotropic materials, so the material type of C1045 and BFPC is set as "Isotropic elasticity" and the relevant material parameters are defined during simulation analysis. The elastic modulus and shear modulus of virtual material are independent, so the "Orthotropic elasticity" material type is used to simulate the virtual material's properties and set its equivalent performance parameters according to Table 1. As described in Section 3, the virtual material layer and the BFPC bed parts are fixed, so the contact type of the virtual material layer and the steel rail is bound, and the contact type of the virtual material layer and the BFPC bed base is also bound. The "Sweep" method is used to mesh the BFPC bed model. The virtual material layer is divided into three layers along the thickness direction. The overall grid of the BFPC bed is shown in Figure 13 (a), and the grid of the virtual material layer is shown in Figure 13 (b). The BFPC bed is fixed on a horizontal plane, so a fixed constraint is added to the surface of the BFPC bed that contacts the ground. The modal analysis result of the BFPC bed is shown in Figure 14.

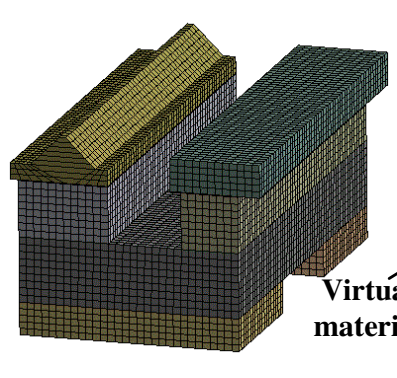

(a)

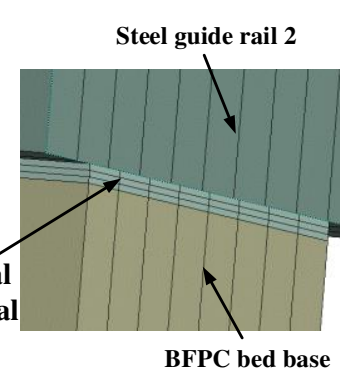

(b)
Figure 13 Finite element mesh model of BFPC bed

According to Figure 14, the first modal frequency of the BFPC bed obtained by simulation is $567.72 \mathrm{~Hz}$, the 
second modal frequency is $895.92 \mathrm{~Hz}$, and the third modal frequency is $1168.5 \mathrm{~Hz}$. The simulated vibration shapes of the BFPC bed are consistent with the experimental vibration shapes. Figure 15 shows the relative error between the simulation frequency and the experimental frequency of the BFPC bed. The modal frequency of the simulation results is slightly higher than the experimental results. The relative error of the two methods is relatively small, ranging from 5.58\% 6.23\%. Therefore, the validity and accuracy of the virtual material method are verified. The main reasons for the error of virtual material method are as follows:

(1) BFPC bed base is made by pouring technology. During manufacturing, the BFPC base may have some pores or bubbles in the bed due to partial incomplete pouring. These reasons lead to the decrease of the overall rigidity of the BFPC bed, which reduces the experimental frequency and causes errors.

(2) The unit normal contact stiffness and unit tangential contact stiffness of the BFPC joint surface are obtained by testing the steel-BFPC joint surface specimens. These test results may have a little error with the steel-BFPC joint surface of BFPC bed, which may lead to deviations in the simulation results.

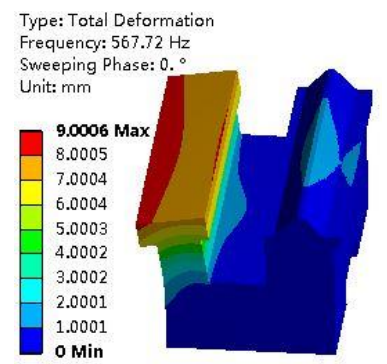

(a) First-order mode

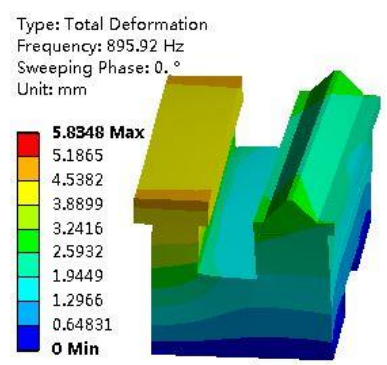

(b) Second-order mode

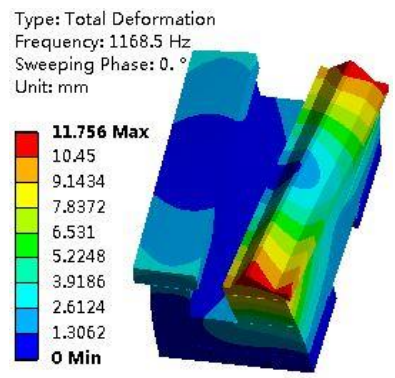

(c) Third-order mode

Figure 14 Modal simulation results of BFPC bed

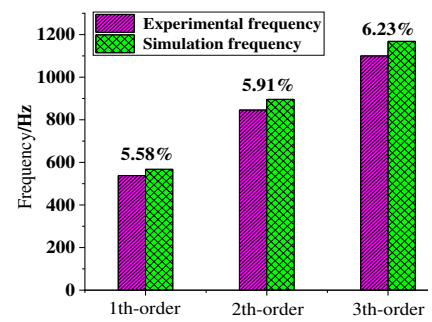

Figure 15 relative error of experimental frequency and simulation frequency

\section{Conclusion}

(1) The principle and method of measuring the contact parameters of steel BFPC joint surface are studied in this paper. The virtual material model of steel BFPC interface is established by theory, and the calculation formulas of equivalent elastic modulus, equivalent shear modulus, equivalent density, Poisson's ratio and virtual layer thickness are obtained.

(2) The modal performance of steel BFPC bed is studied by experiment and virtual material simulation method. The relative error between simulation results and experimental results is $5.58 \%$ $\sim 6.23 \%$, which proves the effectiveness and accuracy of the theory and simulation method of virtual material method.

\section{Acknowledgements}

The authors sincerely thanks to reviewers for his critical discussion and reading during manuscript preparation.

\section{Funding}

Supported by National Natural Science Foundation of China (Grant No. 52005238, 51375219), Project funded by the Education Department of Liaoning Province (Grant No. LJ2019JL030), Project funded by Science and Technology of Liaoning Province (2020-BS-256). 


\section{Authors' contributions}

The author' contributions are as follows: Jiaxing Shen assisted in simulation analysis and proofreading of the paper; $\mathrm{Yu}$ Chen wrote the manuscript; Ping $\mathrm{Xu}$ and Ying-Hua $\mathrm{Yu}$ formulated the experimental plan; Xing-Yuan Zhang and Xiao-Jing $\mathrm{Li}$ assisted in the experimental analysis.

\section{Competing interests}

The authors declare no competing financial interests.

\section{References}

[1] Z Chen, R L Peng, J Zhou, et al. Effect of machining parameters on cutting force and surface integrity when high-speed turning $\mathrm{AD}$ $730^{\mathrm{TM}}$ with PCBN tools. The International Journal of Advanced Manufacturing Technology, 2019,100(9-12):2601-2615.

[2] K K Singh, V Kartik, R Singh. Modeling of Dynamic Instability Via Segmented Cutting Coefficients and Chatter Onset Detection in High-Speed Micromilling of Ti6A14V. Journal of Manufacturing Science \& Engineering, 2016, 139(5):051005.

[3] Y Sun, Z J Yu, J K Xu, et al. High speed micro milling machine condition monitoring based on vibration source identification. Journal of Vibration and Shock,2015,34(09):65-70. (in Chinese)

[4] H T Liu, L Wang, W H Zhao. Stiffness Matching Design for Feed System of High-Speed Machine Tool Considering Modal Characteristics. Journal of Xi'an Jiaotong University, 2014,48(01):90-95. (in Chinese)

[5] L Sun, Y L Zhao, Y Liu. Design of High Response Frequency Accelerometer for Intelligent High Speed Machine Tools. Journal of Vibration, Measurement\& Diagnosis,2013,33(S1):157-159. (in Chinese)

[6] Z H Deng, Z Q Liu, X H Zhang. Research of the Science and Technology Development in High-speed and Efficient Processing Field. Journal of Mechanical Engineering,2010,46(23):106-120. (in Chinese)

[7] J X Shen, P Xu, Y H Yu. Dynamic Characteristics Analysis and Finite Element Simulation of Steel-BFPC Machine Tool Joint Surface. Journal of Manufacturing Science and Engineering,2020,142, 011006.

[8] J Yin, J H Zhang, T Wang, et al. Experimental investigation on air void and compressive strength optimization of resin mineral composite for precision machine tool. Polymer Composites, 2018, 39(2): 457-466.

[9] S Cho, H Kim, S Chang, et al. The application of polymer composites to the table-top machine tool components for higher stiffness and reduced weight. Composite Structures, 2011, 93(2): 492-501.

[10] J D Suh, D G Lee. Design and manufacture of hybrid polymer concrete bed for high-speed CNC milling machine. International Journal of Mechanics and Materials in Design, 2008, 4(2): 113-121.

[11] S Ren, Y Dai, X He, et al. Guideway joint surface properties of heavy machine tools based on the theory of similarity. Research Journal of Applied Sciences, Engineering and Technology, 2013, 5, 5230-5236.
[12] S Mezlini, M Belhadjamor. Finite element modeling of RMS roughness effect on the contact stiffness of rough surfaces. Tribology in Industry. 2016,38. 392-401.

[13] H X Chen, G H Dong, Q Yin, et al. A normal contact stiffness model of joint surface based on the fractal theory. Journal of Vibration and Shock,2019,38(08):218-224. (in Chinese)

[14] W Wang, J B Wu, W P Fu, et al. Theoretical and Experimental Research on Normal Dynamic Contact Stiffness of Machined Joint Surfaces. Chinese Journal of Mechanical Engineering, 2016,52(13):123-130. (in Chinese)

[15] S R Ge, H Zhu. Fractals of tribology. Beijing: China Machine Press, 2005.

[16] Q Chen, F Xu, P Liu. Research on fractal model of normal contact stiffness between two spheroidal joint surfaces considering friction factor. Tribology International,2016, 97, 253-264.

[17] R Q Wang, L D Zhu, C X Zhu. Research on fractal model of normal contact stiffness for mechanical joint considering asperity interaction. International Journal of Mechanical Sciences. 2017, S0020740317313504.

[18] K Xu, Y Yuan, L H Zhang. A Normal Contact Stiffness Model of Joint Surface Based on Fractal Theory. Computer Modeling in Engineering \& Sciences. 2019

[19] Y Sun, H Xiao, J Xu. et al. Study on the normal contact stiffness of the fractal rough surface in mixed lubrication. Proceedings of the Institution of Mechanical Engineers, Part J, Journal of Engineering Tribology, 2018, 232, 1604-1617.

[20] R Han, G Li, J Gong, et al.: Experimental verification and comparative analysis of equivalent methods on metal's fixed joint surface. Materials,2019, 12, 2381.

[21] J J Chen, Y Yuan, Y Cheng. Scale Dependent Normal Contact Stiffness Fractal Model of Joint Joint surfaces. Chinese Journal of Mechanical Engineering, 2018,54(21):127-137. (in Chinese)

[22] G H Dong, Q YIN, G F Yin, et al. Research on Dynamics Modeling and Identification of Machine Tool Joints. Chinese Journal of Mechanical Engineering, 2016,52(5):162-168. (in Chinese)

[23] Y H Chen, X L Zhang, S H Wen, et al. Fractal Model for Normal Contact Damping of Joint Surface Considering Elastoplastic Phase. Chinese Journal of Mechanical Engineering, 2019,55(16):58-68. (in Chinese)

[24] K Shi, G Zhang. A parameterized model of fixed joint surface based on virtual material. Journal of Mechanical Science and Technology,2019, 33, 5209-5217.

[25] R Han, G Li, J Gong, et al: Equivalent Method of Joint Surface Based on Persson Contact Theory: Virtual Material Method. Materials,2019, 12, 3150.

[26] A Majumder, B Bhushan. Fractal model of elastic-plastic contact between rough surfaces. ASME Journal of Tribology, 1991,113(1):1-11.

[27] Y Yuan, C Yu, K Liu, L Gan. A revised Majumdar and Bushan model 
of elastoplastic contact between rough surfaces. Applied Surface Science.2017, 425:1138-1157.

[28] L L Zhao, X P Huang, Z W Zhou. Study on Normal Contact Stiffness of Gear Joint Surface Based on Fractal Theory. Chongqing University of Technology (Natural Soience), 2019,33(8):78-83. (in Chinese)

[29] W J Pan, X P Li, M Y Li, et al. Three-dimensional fractal theory modeling of tangential contact stiffness of mechanized joint surfaces. Journal of Vibration Engineering,2017,30(04):577-586. (in Chinese)

[30] Y H Chen, X L Zhang, S H Wen, et al. Fractal Model for Normal Contact Damping of Joint Surface Considering Elastoplastic Phase. Journal of Mechanical Engineering,2019,55(16):58-68. (in Chinese)

[31] S H Wen, X L Zhang, M X Wu, et al. Fractal Model and Simulation of Normal Contact Stiffness of Joint Interfaces and Its Simulation. Transactions of the Chinese Society for Agricultural Machinery, 2009,40(11):197-202. (in Chinese)

[32] X Y Guo, Y Zhang, W H Yan, et al. Modal Experiments of Z-Shaped Folding Wing Based on PolyMAX, Journal of Vibration, Measurement \& Diagnosis, 2020,40(02):326-331+420. (in Chinese)

[33] X Q Li, K Chen, G Liu. Finite element modeling and analysis of composite propeller blade based on ANSYS. Acta Materiae Compositae Sinica,2017,34(04):591-598. (in Chinese)

[34] Z Tao, X Zhang, D P Liu. Optimal Design for the Pedestal of CX8075 Turning and Milling Machining Center Based on ANSYS. Journal of Vibration, Measurement \& Diagnosis, 2012,32(06):966-969. (in Chinese)

[35] M Wang, X Y Zhang, T Zan, et al. Investigation of Static and Dynamic Characteristics of a High-speed Electric Spindle Based on ANSYS. Journal OF Beijing University of Technology,2012,38(07):988-991. (in Chinese)

\section{Biographical notes}

Jia-Xing Shen, born in 1990, is a lecturer and master tutor at Research Institute of Technology and Equipment for the Exploitation and Utilization of Mineral Resources, Liaoning Technical University, China. He received his $\mathrm{PhD}$ degree from Liaoning Technical University, China, in 2018. His main research interests include mechanical system dynamics analysis and control.

Tel: +86-13841824339; E-mail: shenjiaxing@lntu.edu.cn, 329833309@qq.com
Yu Chen, born in 1991, is a lecturer at the college of

Mechanical Engineering, Chaohu University. He received his master's degree from Liaoning Technical University, China, in 2018. He's studying in Liaoning Technical University for a doctorate, in 2020. His research interests are mechanical system dynamics analysis and control.

Email: cy3059555@163.com

Ping Xu, born in 1964, is currently a professor and a $\mathrm{PhD}$ candidate supervisor at School of Mechanical Engineering, Liaoning Technical University, China. His main research interests include mechanical system dynamics analysis and control.

E-mail: lnxuping@163.com

Xing-Yuan Zhang, born in 1980, is currently an associate professor and master tutor at School of Mechanical Engineering, Liaoning Technical University, China. His main research interests include mechanical friction and wear.

E-mail: zxyuan001@163.com

Ying-Hua Yu, born in 1965, is currently a professor and a PhD candidate supervisor at School of Mechanical Engineering, Liaoning Technical University, China. Her main research interests include mechanical system dynamics analysis and control.

E-mail: xuvicky199128@163.com

Xiao-Jing Li, born in 1988, is a lecturer of Key Lab of Intelligent Equipment Digital Design and Process Simulation, Hebei Province, Tangshan University, China. She received her PhD degree from Liaoning Technical University, China, in 2019. Her research interests include mechanical system dynamics analysis and control.

E-mail: lixiaojingre@163.com 


\section{Figures}

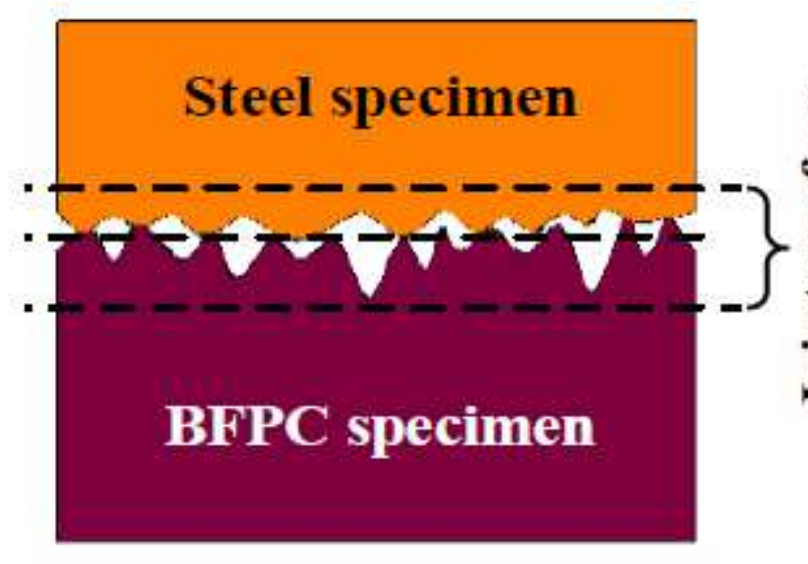

(a)

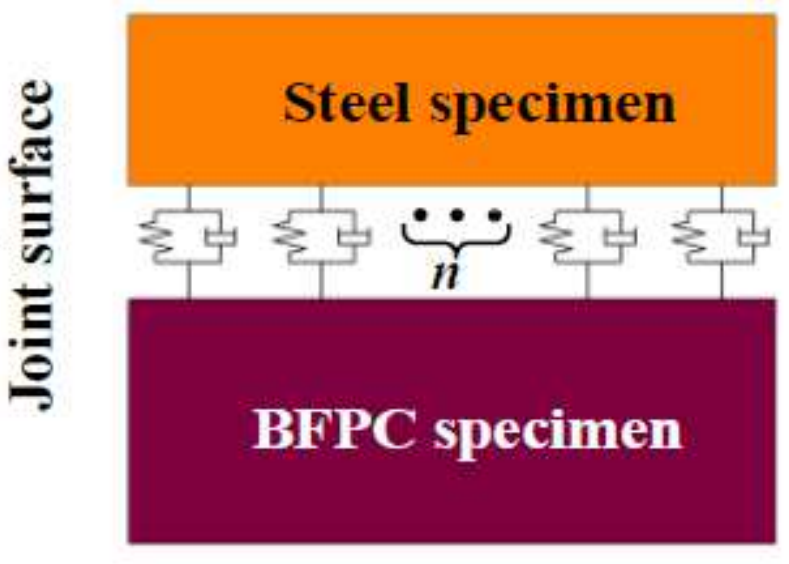

(b)

Figure 1

Equivalent model of steel-BFPC joint surface

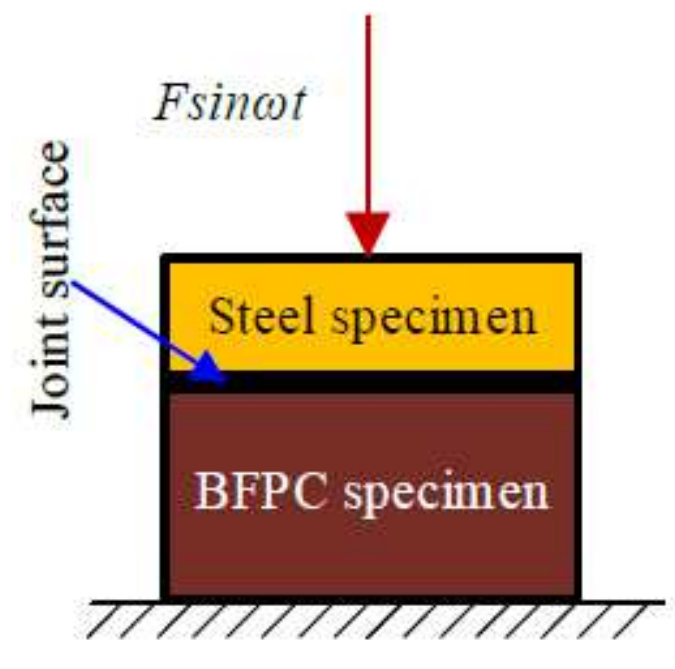

(a)

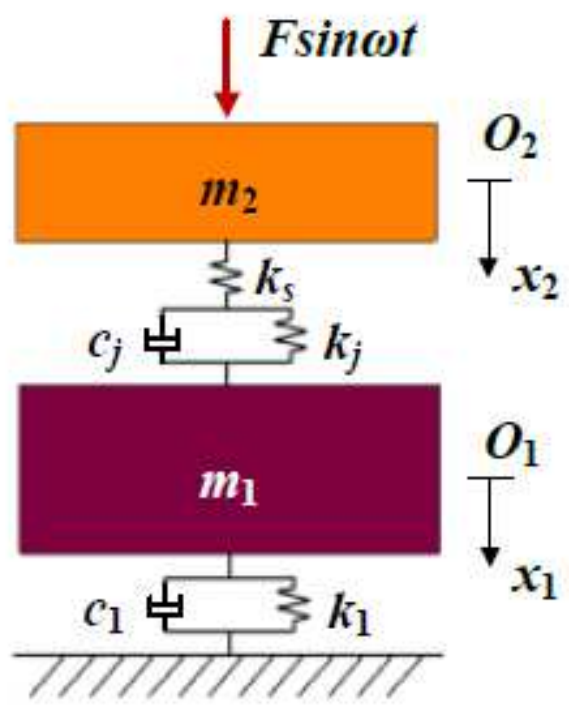

(b)

Figure 2

Steel-BFPC joint surface and its equivalent dynamic model 


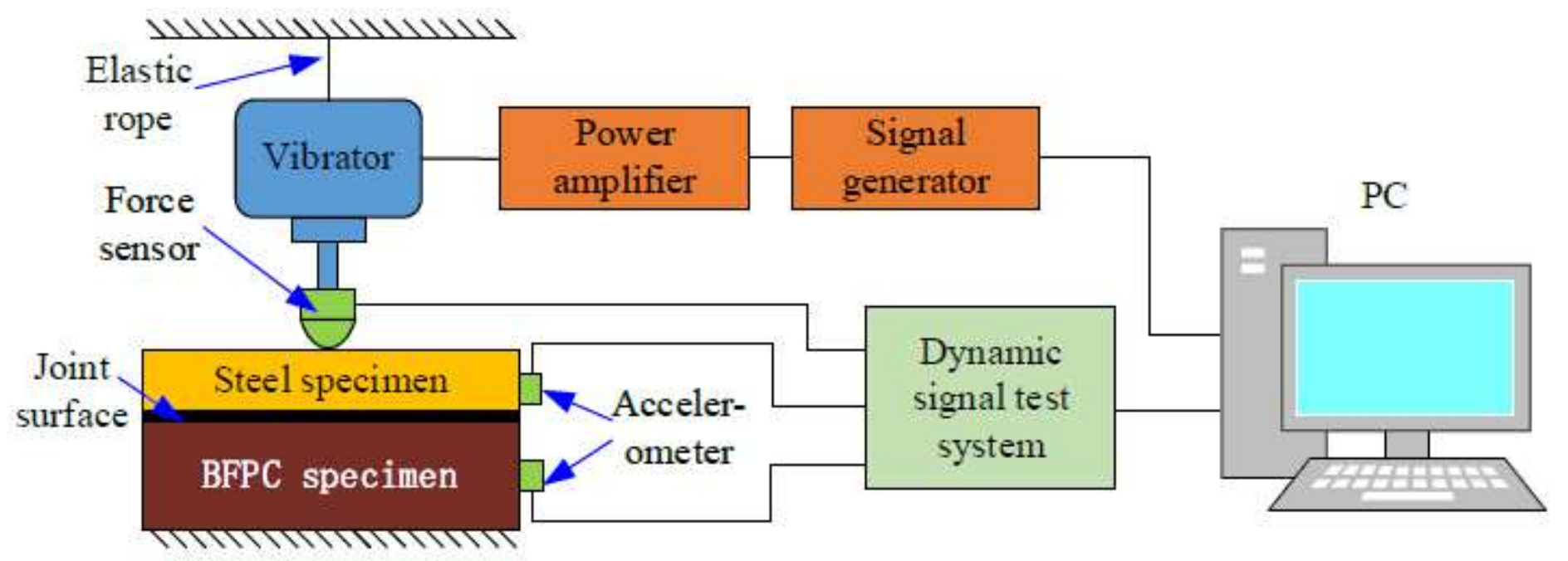

Figure 3

The principle of joint surface parameter detection

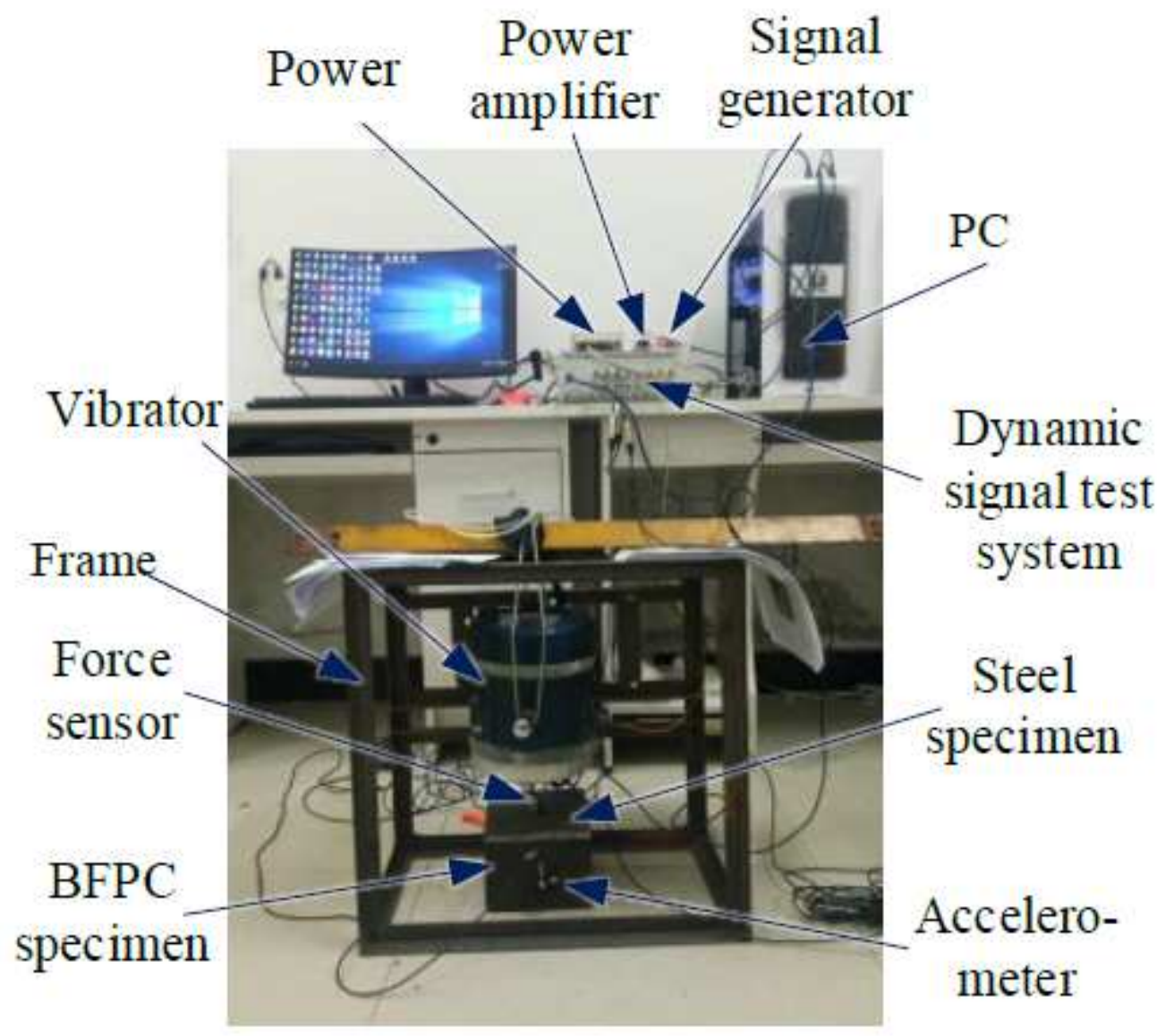

Figure 4

Experimental site 


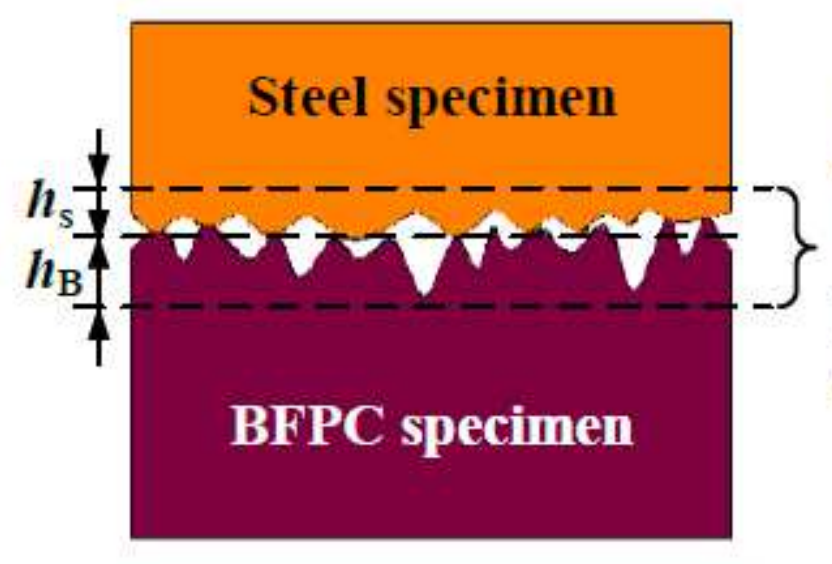

(a)

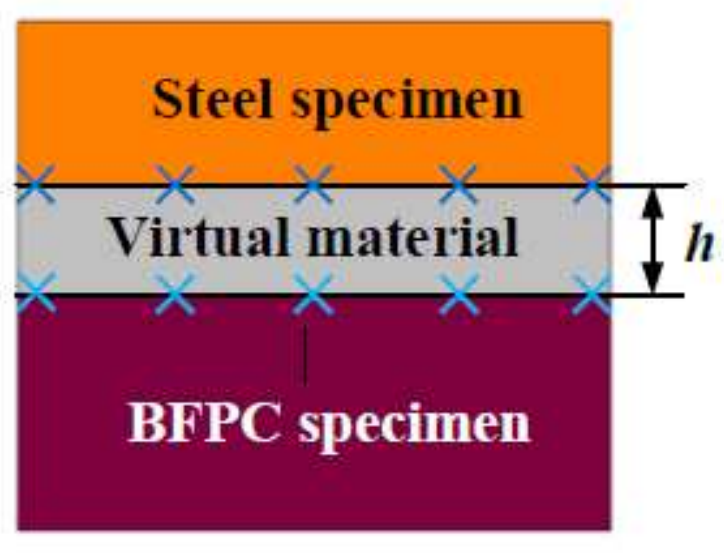

(b)

Figure 5

Virtual material model of steel-BFPC joint surface

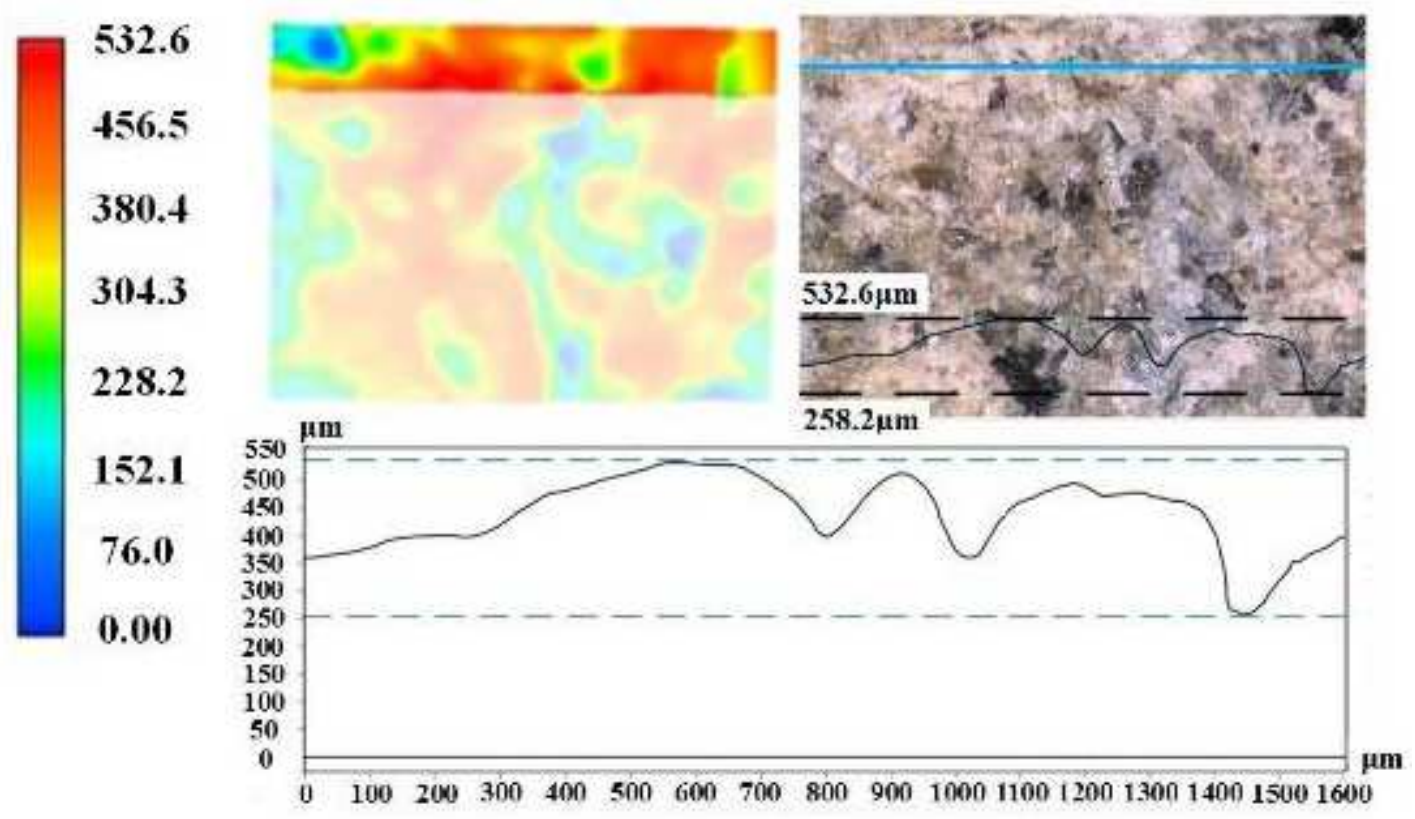

Figure 6

Surface morphology of BFPC 


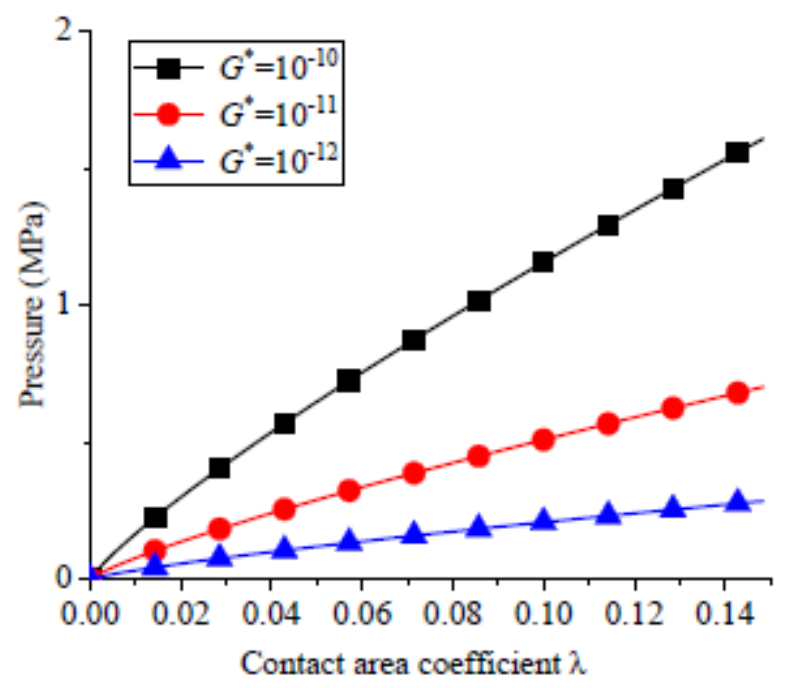

(a) $\mathrm{Ra} 3.2$

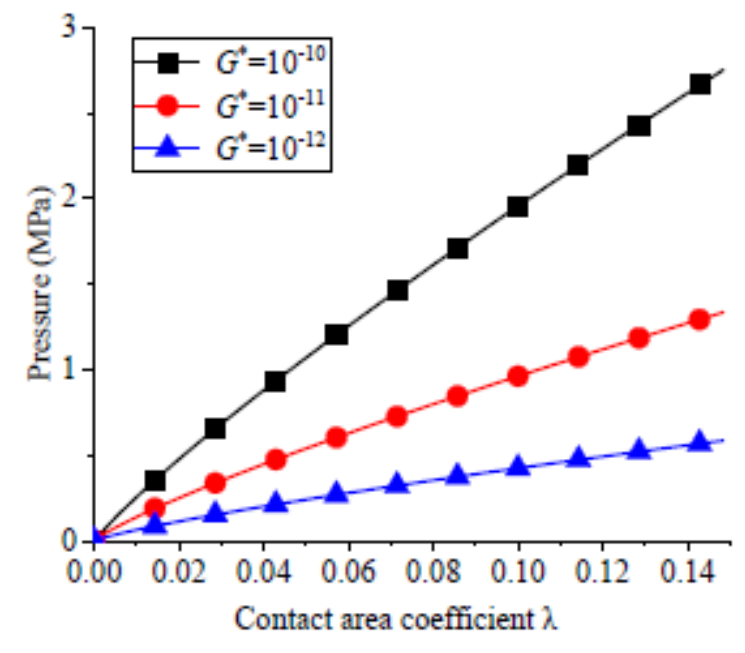

(b) Ra 6.3

Figure 7

Relationship between the contact area coefficient of the joint surface and the pressure 


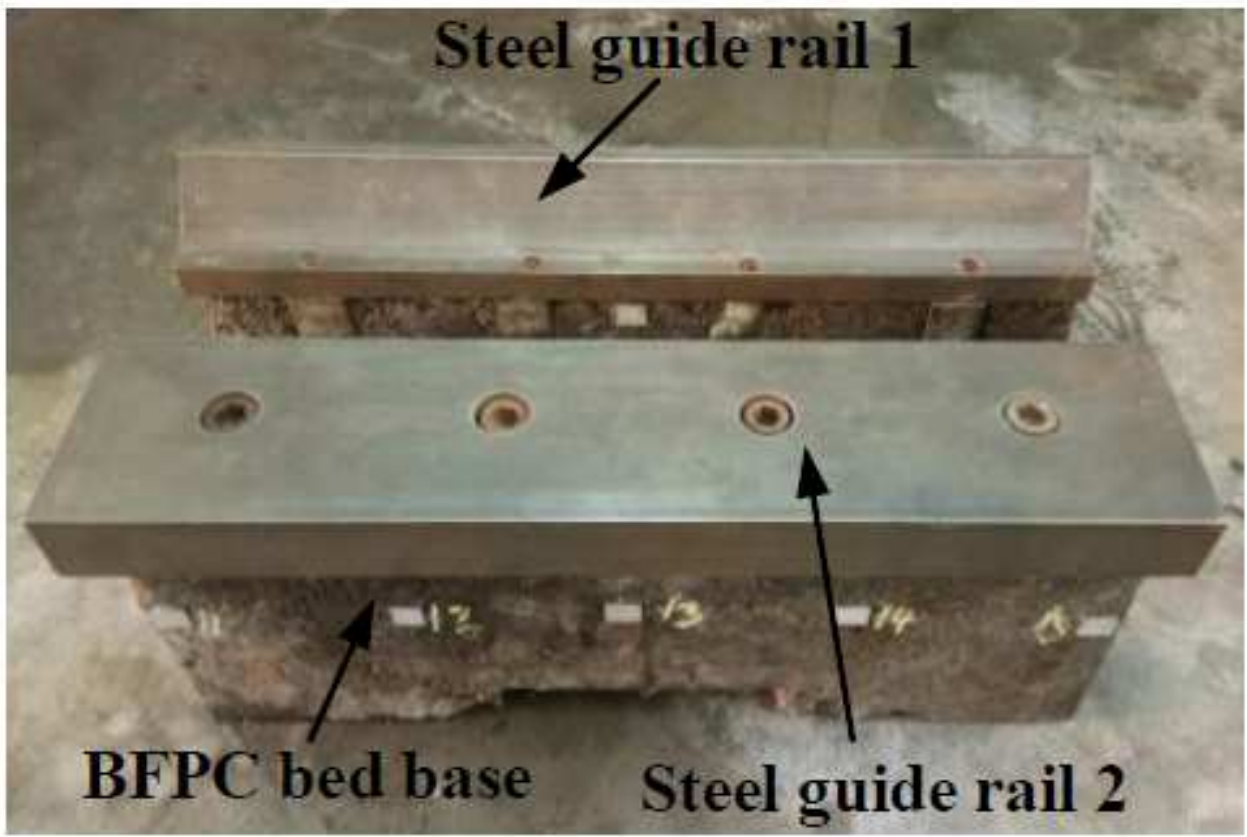

Figure 8

BFPC bed

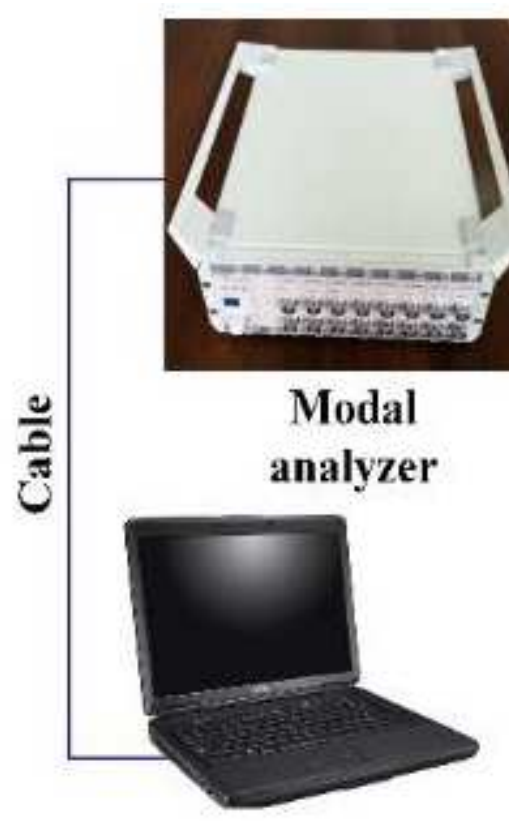

Computer

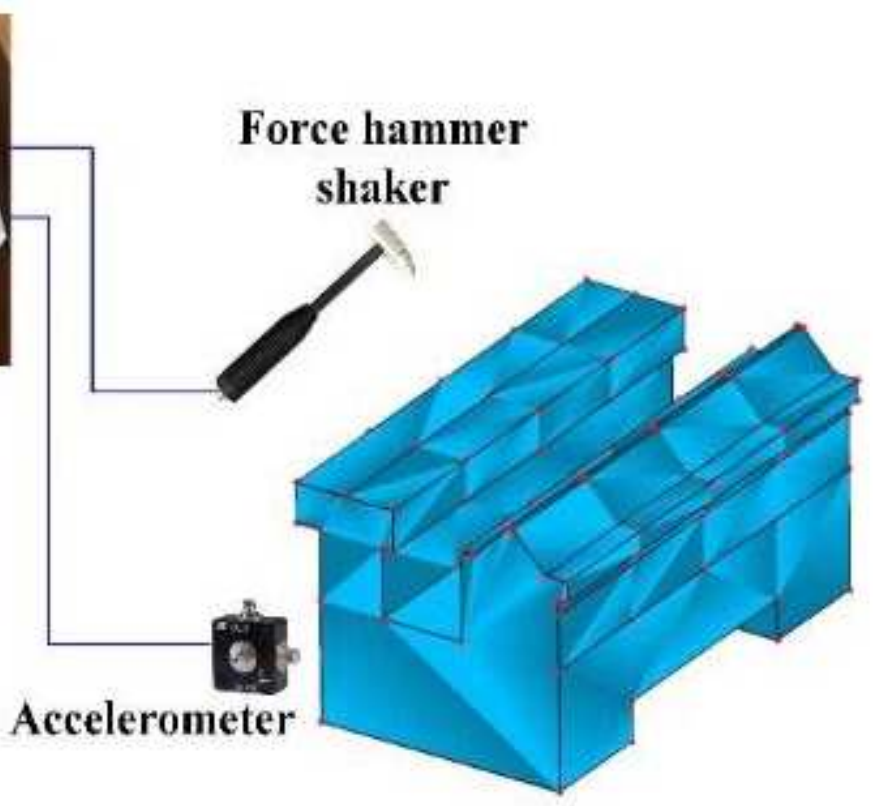

BFPC bed

Figure 9

BFPC modal performance detection system 


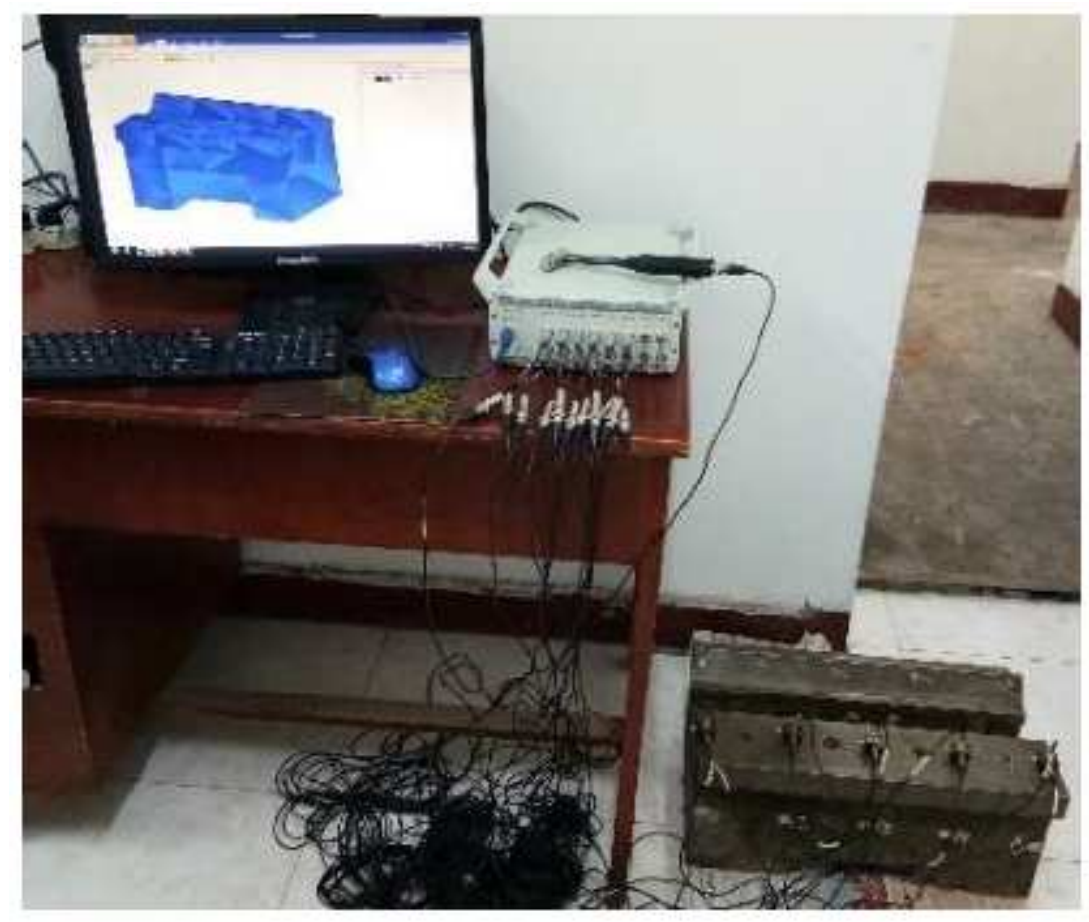

Figure 10

Modal experiment site of BFPC bed 


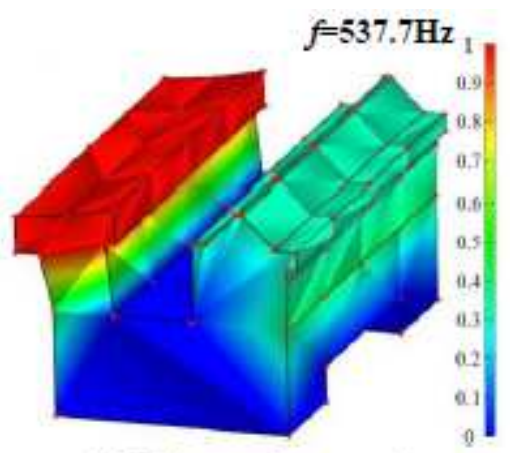

(a) First-order mode

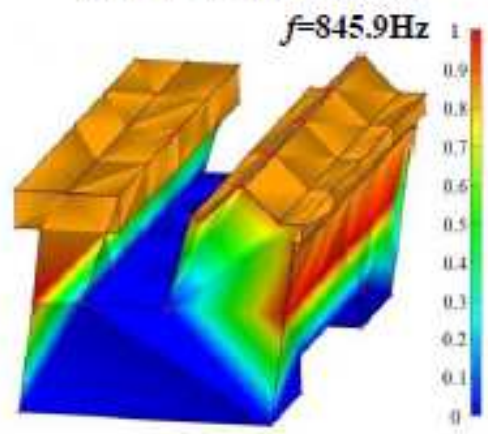

(b) Second-order mode

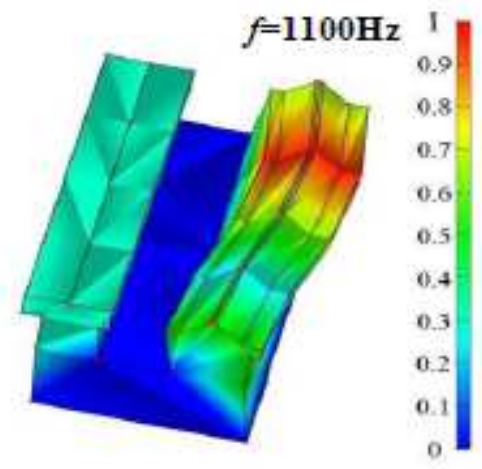

(c) Third-order mode

Figure 11

Experimental mode shape of BFPC bed 


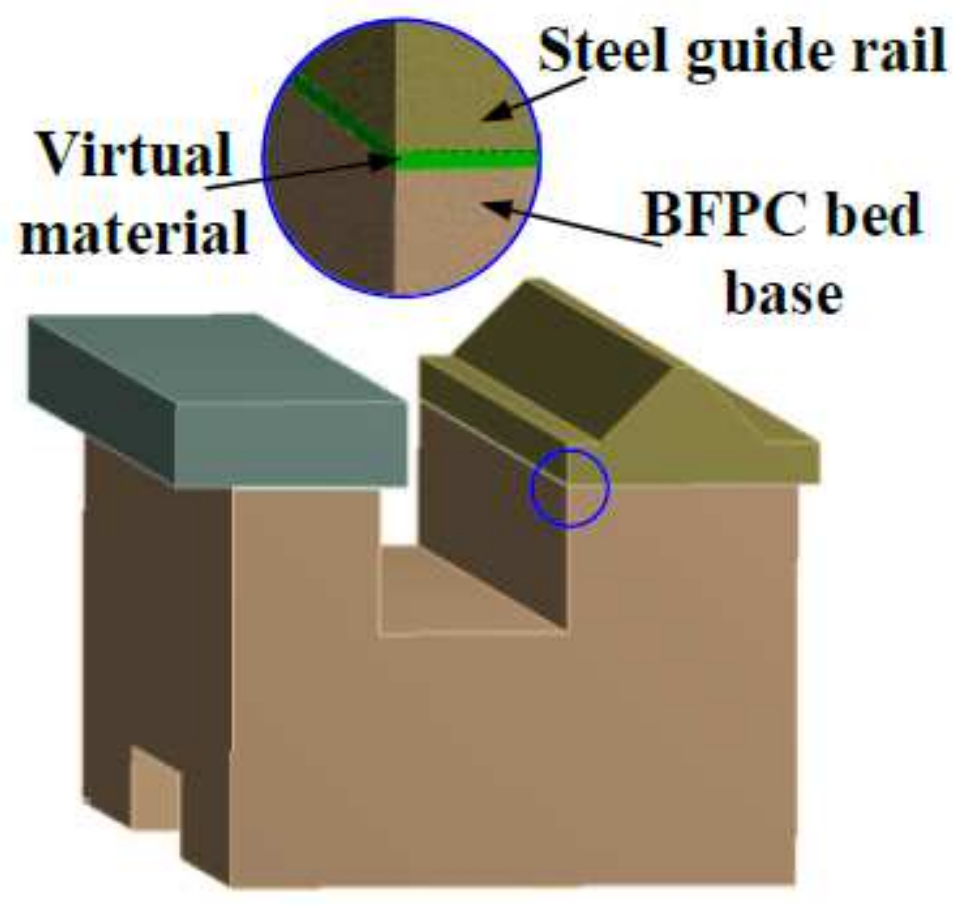

Figure 12

The virtual material model of the BFPC bed

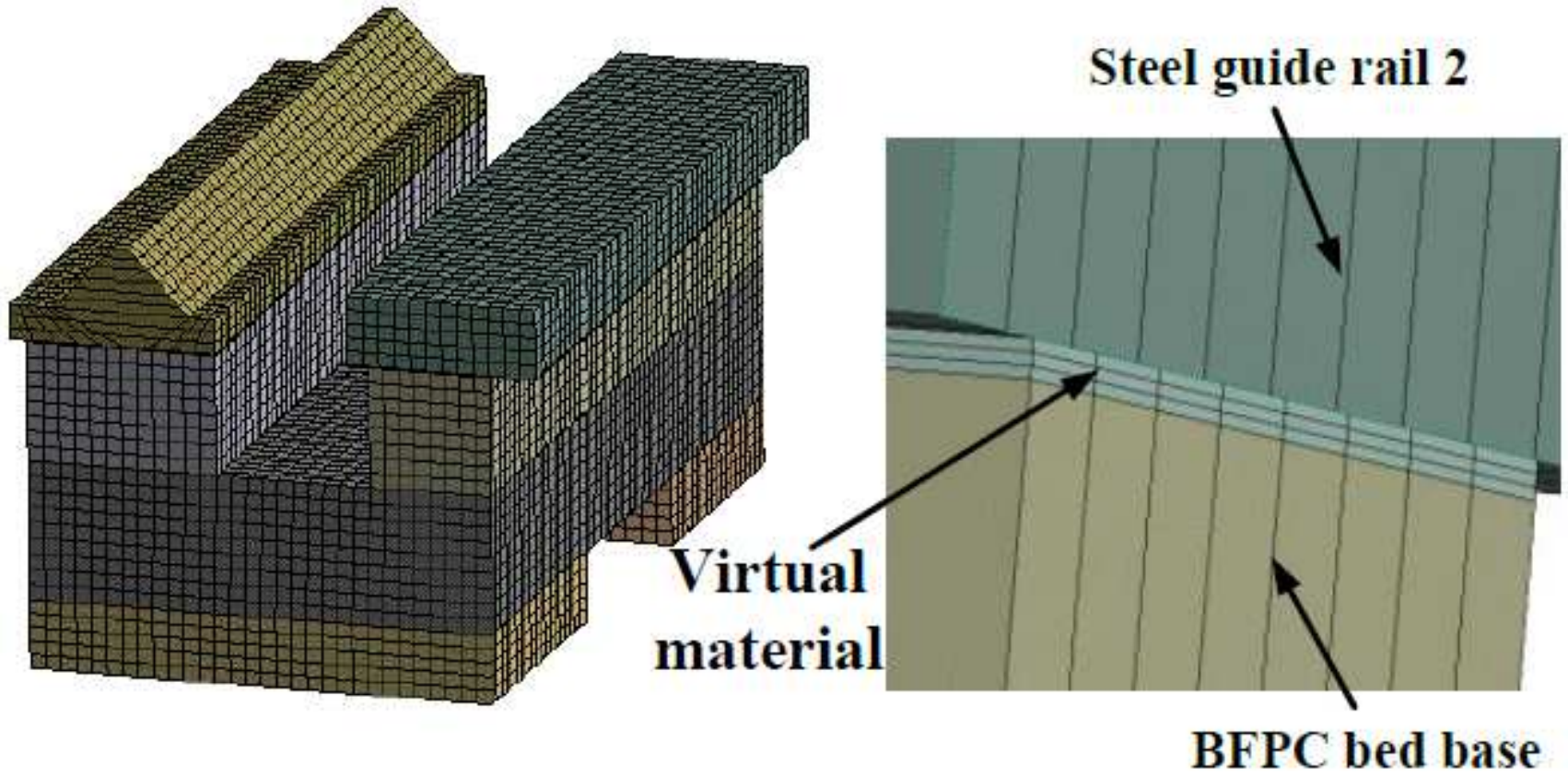

(a)

(b)

Figure 13

Finite element mesh model of BFPC bed 
Type: Totel Deformation

Frequeng: $567.72 \mathrm{~Hz}$

Sweeping Phase: 0 .

Unit: $\mathrm{mm}$

9.0006 Max

8.0005

7.0004

5.0004

5.0003

4.0002

3.0002

2.0001

1.0001

0 Min

\section{(a) First-order mode}

Type: Total Deformstion

Frequency: $895.92 \mathrm{~Hz}$

Sweeping Phase: 0.0

Unit: $\mathrm{mm}$

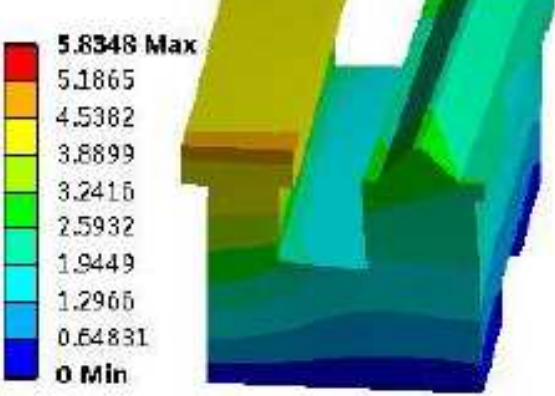

(b) Second-order mode

Type: Total Deformation

Frequency: $1168.5 \mathrm{~Hz}$

Sweeping Fhase: $0 .{ }^{\circ}$

Unit: $\mathrm{mm}$

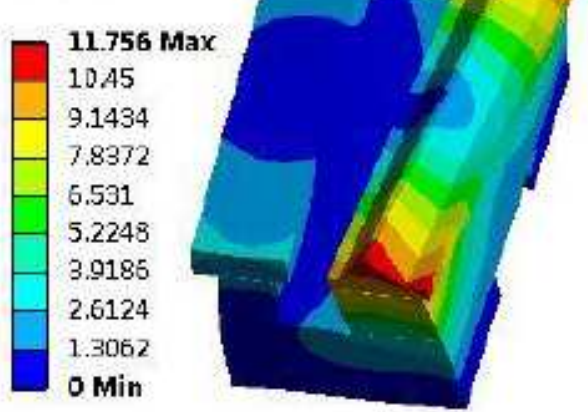

(c) Third-order mode

Figure 14

Modal simulation results of BFPC bed 


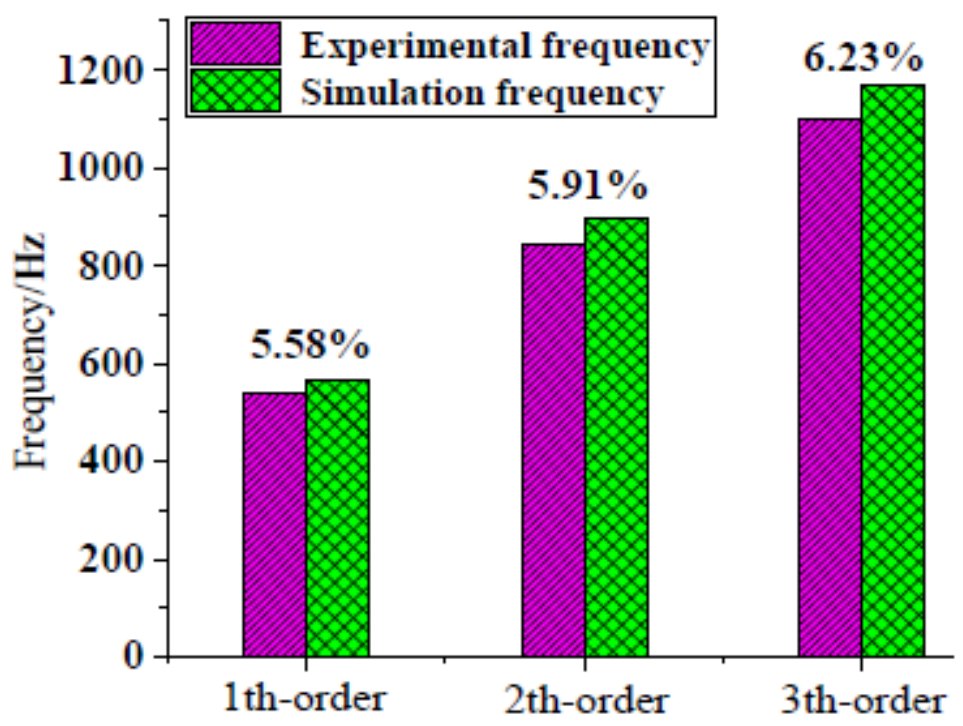

Figure 15

Relative error of experimental frequency and simulation frequency 